\title{
Local injection of dexamethasone helping to prevent lower back pain after epidural delivery analgesia
}

\author{
ZHAOXIA YANG ${ }^{1}$, LANLAN LIU $^{1}$, JINMEI MU $^{1}$, WENCHEN GUO ${ }^{1}$, \\ SHUNRONG $\mathrm{LI}^{2}$, YANYAN JING ${ }^{3}$ and YANYAN LIU ${ }^{1}$ \\ ${ }^{1}$ Department of Obstetrics (II), People's Hospital of Rizhao, Rizhao, Shandong 276800; ${ }^{2}$ Intensive Care Unit, \\ and ${ }^{3}$ Department of Obstetrics, People's Hospital of Zhangqiu District, Jinan, Shandong 250200, P.R. China
}

Received January 11, 2018; Accepted July 30, 2018

DOI: $10.3892 /$ etm.2018.6623

\begin{abstract}
This report aims to retrospectively analyze the clinical effect of local pretreatment with dexamethasone (DXMS) on lower back pain after epidural labor analgesia. Patients with epidural labor analgesia treated in People's Hospital of Rizhao from January 2014 to December 2016 were studied. All 368 cases involved were pregnant primipara with full-term single birth. Parturient received injection of DXMS and lidocaine mixture around the epidural puncture point was the observation group $(n=188)$, and parturient received injection of $0.9 \%$ sodium chloride and lidocaine mixture around the epidural puncture point was the control group $(n=180)$. The incidence and degree of lower back pain postoperatively in the two groups were evaluated by pain visual analogue scale method. The incidence of lower back pain at $48 \mathrm{~h}, 72 \mathrm{~h}$ after operation in observation group was significantly lower than that in control group $(\mathrm{p}<0.05)$. Among patients undergoing one puncture and more than one puncture, the incidence of postoperative lower back pain in the observation group was significantly lower than that in the control group $(59.26 \%)$ $(\mathrm{p}<0.05)$. Among the parturient with spontaneous delivery, the incidence of postoperative lower back pain in the observation group was significantly lower than that in the control group $(\mathrm{p}=0.028)$. Among the cesarean section patients, the incidence of pain in observation group was significantly lower than that in control group ( $\mathrm{p}=0.019)$. At 48 and $72 \mathrm{~h}$ after operation, severe pain in the observation group was significantly less than that in the control group $(\mathrm{p}<0.05)$. DXMS local pretreatment can significantly reduce the incidence of postoperative lower back pain and the degree of pain after epidural delivery analgesia. DXMS pretreatment in epidural analgesia deserved to be widely used clinically.
\end{abstract}

Correspondence to: Dr Yanyan Liu, Department of Obstetrics (II), People's Hospital of Rizhao, 126 Taian Road, Rizhao, Shandong 276800, P.R. China

E-mail: yth5xf@163.com

Key words: DXMS, labor analgesia, epidural, pretreatment, lower back pain

\section{Introduction}

Lower back pain is a common complication of postoperative epidural analgesia, and the incidence is $2-31 \%$ (1), especially in women with cesarean section, whose incidence of lower back pain is as high as $35 \%$ (2). Mild pain can cause insomnia and anxiety. In severe cases, it can even cause tearing pain in the waist, which brings about tremendous physical and psychological trauma to the mother. It is also possible that lower back pain turns into chronic pain, disturbing parturient for a long time and having a negative effect on quality of their lives (3). In general, the treatment of postoperative lower back pain is patient-controlled epidural analgesia and intravenous controlled analgesia (4). Although the two treatment methods can relieve pain after maternal, they have no preventive effect on postoperative lower back pain. Therefore, it is considered that whether there is a way that can effectively prevent the occurrence of lower back pain, or can effectively reduce the degree of pain. In the study of Salem et al (5), dexamethasone (DXMS) was shown to be effective in reducing adverse anesthesia during cesarean delivery. Thus whether DXMS also reduces back pain following epidural delivery analgesia is considered. DXMS is a kind of steroid hormones, and its role is similar to glucocorticoid, commonly used in the local treatment of chronic pain. DXM also has significant preventive effect on postpartum hemorrhage in cesarean section (6). There are also studies showing that DXMS is conducive for combined spinal-epidural analgesia cesarean section (7), which indicates that DXMS has been widely used in pregnant women and its safety has been guaranteed. DXMS has a variety of therapeutic effects, but there are few researches about its effect on postoperative epidural analgesia lower back pain. To determine the effect of DXMS local pretreatment on epidural puncture point on the prevention of postoperative lower back pain after epidural analgesia, the following statistical analysis was performed.

\section{Materials and methods}

General information. A total of 368 parturient women admitted into People's Hospital of Rizhao (Rizhao, China) from January 2014 to December 2016 undergoing epidural labor analgesia were included for the study. A total of 188 patients treated with 
DXMS and lidocaine mixture around the epidural puncture point were enrolled into the observation group, with a mean age of (27.2 \pm 4.7$)$ years; a total of 180 patients treated with $0.9 \%$ sodium chloride injection and lidocaine mixture around the epidural puncture point were enrolled in the control group, with a mean age of $(28.3 \pm 4.9)$ years.

Epidural analgesia for labor was applied on parturients who were primipara with full term single live fetus, aged 22 to 35 years old, in full compliance with epidural anesthesia contraindications and indications, and in line with American Society of Anesthesiologists ASA grading (8) I-II level. Exclusion for the following cases: patients allergic or resistant to DXMS, patients with digestive diseases and in active phases; patients with abnormalities in adrenocortical function; patients with abnormalities in liver and kidney function; patients with a history of pre-eclampsia, diabetes, gestational hypertension; patients with mental disorders or abnormal brain judgments; patients failed for epidural analgesics. The postoperative lower back pain condition at 48 and $72 \mathrm{~h}$ after operation and the general conditions such as gender, height, weight were recorded. The study obtained the medical Ethics Committee's approval of People's Hospital of Rizhao, and all patients and their relatives signed the informed consent form.

Treatment. Parturient was given oxygen immediately after entering the delivery room. Routine monitoring of vital signs was performed. When the cervix was open to $3-5 \mathrm{~cm}$, epidural catheterization anesthesia was immediately performed. Routine disinfection and towels were placed, patients were right arm reclining and received anesthesia at L3 and L4. Pretreatment for patients in the observation group was the injection of lidocaine $(4 \mathrm{ml})$ and DXMS $(1 \mathrm{ml})$ mixture around the puncture point, patients in the control group were given the injection of lidocaine $(4 \mathrm{ml})$ and $0.9 \%$ sodium chloride mixture as the pretreatment. Then anesthesia and puncture were performed, an epidural catheter was placed, patients were injected with $0.2 \%$ ropivacaine $(10 \mathrm{ml})$ and maintained at $10 \mathrm{ml} / \mathrm{h}$ with $0.1 \%$ ropivacaine $+2 \mu \mathrm{g} / \mathrm{ml}$ fentanyl. The drug was immediately stopped when the cervix was fully opened.

During the delivery, if prolonged labor or stagnation occurred, the parturient was moved to the operation room immediately for cesarean section. Narcotic drug was lidocaine hydrochloride injection (SFDA approval no. H37022147; Shandong Hualu Pharmaceutical Co., Ltd., Liaocheng, China), specifications: $5 \mathrm{ml}$ : $0.1 \mathrm{~g}$; DXMS sodium phosphate injection (SFDA approval no. H41021255; Suicheng Pharmaceutical Co., Ltd., Zhengzhou, China), specifications: $1 \mathrm{ml}: 5 \mathrm{mg}$; Ropivacaine (SFDA approval no. H20100126; Jiangsu Hengrui Pharmaceutical Co., Ltd., Nanjing, China), specifications: 20 mg/10 ml/U, fentanyl (Zhunzi H20030199; Yifan Renfu Pharmaceutical Co., Ltd., Shanghai, China), specifications: $2 \mathrm{ml}: 0.1 \mathrm{mg}$. The implementation standard was Chinese Pharmacopoeia 2015 edition two (9).

Observation index. Postoperative lower back pain was assessed by using the Visual Analogue Scale/Score (VAS) (10), defined as mild pain at 1-3 scores moderate pain at 4-6 scores, severe pain at 7-10 scores.

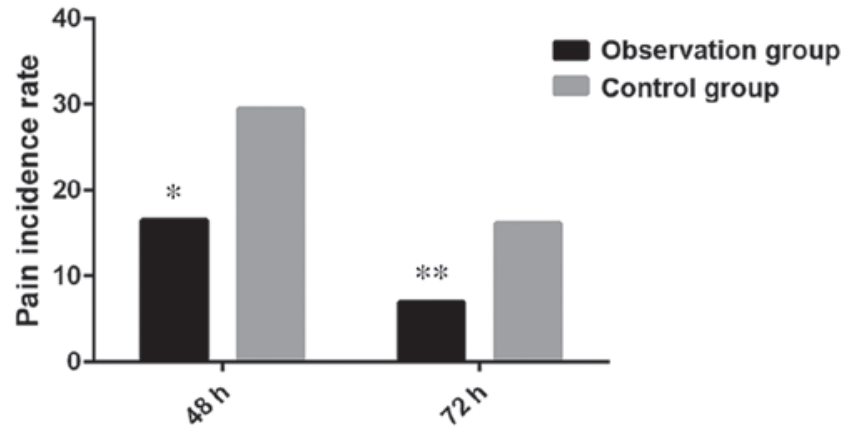

Figure 1. The incidence of lower back pain at 48 and $72 \mathrm{~h}$ after operation in both groups. In the comparison of the incidence of lower back pain at $48 \mathrm{~h}$ after operation in the observation group and the control group, $" \mathrm{p}=0.032$; in the comparison of the incidence of lower back pain in the observation group and the control group at $72 \mathrm{~h}$ after operation, ${ }^{* *} \mathrm{p}=0.036$.

Statistical analysis. SPSS 19.0 (IBM, Armonk, NY, USA) was used for statistical analysis. The enumeration data was expressed as percentage. The measurement data were expressed as mean $\pm \mathrm{SD}$. The comparison between measurement data was performed by t-test. The rate was compared by Chi-square test. $\mathrm{p}<0.05$ represented the difference was statistically significant.

\section{Results}

Clinical data. A total of 368 patients with labor analgesia were enrolled, 188 cases were in the observation group and 180 cases in the control group. There was no significant difference in the basic data of maternal age, height, weight, education, residence, exercise habits, ethnicity, mode of delivery, puncture times and ASA grade between the two groups ( $>0.05)$. The factors between the two group were comparable. The clinical data of two groups can be seen from Table I.

Comparison of postoperative lower back pain incidence. There were $36(19.15 \%)$ cases of lower back pain in the observation group and 67 (37.22\%) cases of the lower back pain in the control group at 48 hours after operation. There were $18(9.57 \%)$ cases of lower back pain in the observation group and $43(23.89 \%)$ cases of the lower back pain in the control group at $72 \mathrm{~h}$ after operation. There was a significant difference in the incidence of lower back pain between the two groups ( $\mathrm{p}=0.032)$ at $48 \mathrm{~h}$ after operation. The incidence of lower back pain at $72 \mathrm{~h}$ after operation between the two groups was significantly different $(\mathrm{p}=0.036)$. DXMS pretreatment can reduce the incidence of post-partum back pain in patients with epidural analgesia (Fig. 1).

Effect of DXMS anesthesia on parturient with different puncture times. In the observation group, the number of patients undergoing one puncture was 160, of which 28 patients had postoperative lower back pain; there were 28 patients undergoing more than 1 punctures, of which 8 patients had postoperative lower back pain. In the control group, the number of patients undergoing one puncture was 153, of which 51 patients had postoperative lower back pain; there were 27 patients undergoing more than 1 punctures, 
Table I. Clinical data of two groups of patients.

\begin{tabular}{|c|c|c|c|c|}
\hline Item & Observation group [n (\%)] & Control group [n (\%)] & $t / \chi^{2}$ & $\mathrm{p}$-value \\
\hline Age (year) & & & 0.876 & 0.411 \\
\hline$<28$ & $112(59.57)$ & $109(60.56)$ & & \\
\hline$\geq 28$ & $76(40.43)$ & $71(39.44)$ & & \\
\hline Height $(\mathrm{cm})$ & & & 0.175 & 0.969 \\
\hline$<160$ & $120(63.83)$ & $126(70.00)$ & & \\
\hline$\geq 160$ & $68(36.17)$ & $54(30.00)$ & & \\
\hline Weight (kg) & & & 0.956 & 0.396 \\
\hline$<55$ & $96(51.06)$ & $93(51.67)$ & & \\
\hline$\geq 55$ & $92(48.94)$ & $87(48.33)$ & & \\
\hline Cultural level & & & 1.363 & 0.517 \\
\hline$\leq$ High school & $95(50.53)$ & $88(48.89)$ & & \\
\hline >High school & $93(49.47)$ & $92(51.11)$ & & \\
\hline Residence & & & 1.336 & 0.522 \\
\hline City & $99(52.66)$ & $88(48.89)$ & & \\
\hline Countryside & $89(47.34)$ & $92(51.11)$ & & \\
\hline Exercise habits & & & 0.933 & 0.393 \\
\hline Yes & $73(38.83)$ & $66(36.67)$ & & \\
\hline No & $115(61.17)$ & $114(63.33)$ & & \\
\hline Puncture times (time) & & & 0.976 & 0.381 \\
\hline 1 & $160(85.11)$ & $153(85.00)$ & & \\
\hline$>1$ & $28(14.89)$ & $27(15.00)$ & & \\
\hline ASA classification & & & 1.147 & 0.311 \\
\hline I & $153(81.38)$ & $150(83.33)$ & & \\
\hline II & $35(18.62)$ & $30(16.67)$ & & \\
\hline Mode of delivery & & & 0.912 & 0.419 \\
\hline Natural production & $135(71.81)$ & $131(72.78)$ & & \\
\hline Cesarean section & $53(28.19)$ & $49(27.22)$ & & \\
\hline
\end{tabular}

Table II. Comparison of the incidence of postoperative lower back pain between the two groups of parturient.

\begin{tabular}{|c|c|c|c|c|c|c|}
\hline \multirow[b]{2}{*}{ Group } & \multicolumn{3}{|c|}{ One puncture } & \multicolumn{3}{|c|}{ More than one puncture } \\
\hline & $\mathrm{n}$ & Without pain $[(\mathrm{n} \%)]$ & Pain $[(\mathrm{n} \%)]$ & $\mathrm{n}$ & Without pain $[(\mathrm{n} \%)]$ & Pain $[(\mathrm{n} \%)]$ \\
\hline Observation group & 160 & $132(82.50)$ & $28(17.50)$ & 28 & $20(71.43)$ & $8(28.57)$ \\
\hline Control group & 153 & $102(66.67)$ & $51(33.33)$ & 27 & $11(40.74)$ & $16(59.26)$ \\
\hline$\chi^{2}$ & & 4.232 & 6.438 & & 4.697 & 7.626 \\
\hline p-value & & 0.033 & 0.018 & & 0.030 & 0.006 \\
\hline
\end{tabular}

of which 16 patients had postoperative lower back pain. Among the patients undergoing one puncture, the incidence of postoperative lower back pain in the observation group $(17.50 \%)$ was significantly lower than that in the control group (33.33\%), and the difference was statistically significant $(\mathrm{p}=0.018)$; among the patients undergoing more than one punctures, the incidence of postoperative lower back pain in the observation group $(28.57 \%)$ was significantly lower than that in the control group (59.26\%), and the difference was statistically significant $(\mathrm{p}=0.006)$ (Table II).
Effect of DXMS in different modes of delivery. In the observation group, the number of spontaneous births was 135, of which 26 patients occurred postoperative lower back pain; the number of cesarean section was 53, among them 10 patients occurred postoperative lower back pain. In the control group, the number of births was 131, of which 48 patients occurred postoperative lower back pain; the number of cesarean section was 49, postoperative lower back pain occurred in 19 patients. Among the spontaneous birth patients, the incidence of postoperative lower back pain in the observation group (19.26\%) was 
Table III. Comparison of postoperative lower back pain incidence between different modes of delivery.

\begin{tabular}{|c|c|c|c|c|c|c|}
\hline \multirow[b]{2}{*}{ Group } & \multicolumn{3}{|c|}{ Spontaneous birth } & \multicolumn{3}{|c|}{ Cesarean section } \\
\hline & $\mathrm{n}$ & No pain $[(\mathrm{n} \%)]$ & Pain [(n \%)] & $\mathrm{n}$ & No pain $[(\mathrm{n} \%)]$ & Pain $[(\mathrm{n} \%)]$ \\
\hline Observation & 135 & $109(80.74)$ & $26(19.26)$ & 53 & 43 (81.13) & $10(18.87)$ \\
\hline Control & 131 & $83(63.36)$ & $48(36.64)$ & 49 & $30(61.22)$ & $19(38.78)$ \\
\hline$\chi^{2}$ & & 4.667 & 4.213 & & 4.888 & 6.434 \\
\hline p-value & & 0.031 & 0.028 & & 0.021 & 0.019 \\
\hline
\end{tabular}

Table IV. Comparison of VAS scores at $48 \mathrm{~h}$ and $72 \mathrm{~h}$.

$48 \mathrm{~h}$

$72 \mathrm{~h}$

n Mild [(n \%)] $\quad$ Moderate [(n \%)] $\quad$ Severe [(n \%)] n $\quad$ Mild [(n \%)] $\quad$ Moderate [(n \%)] Severe [(n \%)]

\begin{tabular}{lcccccccc}
\hline Observation & 36 & $20(55.56)$ & $13(36.11)$ & $3(8.33)$ & 18 & $14(77.78)$ & $3(16.67)$ & $1(5.56)$ \\
Control & 67 & $19(28.36)$ & $33(49.25)$ & $15(22.39)$ & 43 & $5(11.63)$ & $25(58.14)$ & $13(30.23)$ \\
$\chi^{2}$ & & 6.435 & 4.232 & 4.886 & & 7.624 & 6.756 & 6.331 \\
p-value & & 0.012 & 0.026 & 0.021 & & 0.007 & 0.009 & 0.014 \\
\hline
\end{tabular}

significantly lower than that in the control group (36.64\%), and the difference was statistically significant $(\mathrm{p}=0.028)$. Among the cesarean section patients, the incidence of lower back pain in observation group (18.87\%) was significantly lower than that in control group (38.78\%), the difference was statistically significant $(\mathrm{p}=0.019)$ (Table III).

Comparison of VAS score. At $48 \mathrm{~h}$ after operation, there were 36 cases of postoperative lower back pain in the observation group, including 20 cases of mild pain, 13 cases of moderate pain and 3 cases of severe pain. In the control group, there were 67 cases of postoperative lower back pain, including 19 cases of mild pain, 33 cases of moderate pain and 15 cases of severe pain. At $72 \mathrm{~h}$ after operation, 18 maternal postoperative lower back pain patients were observed in the observation group, including 14 mild pains, 3 moderate pains and 1 severe pain. In the control group, 43 cases of maternal postoperative lower back pain were observed, including 5 cases of mild, 25 cases of moderate, 13 cases of severe pain. There was significant difference between the two groups in terms of different degrees of lower back pain at $48 \mathrm{~h}, 72 \mathrm{~h}$ after operation $(\mathrm{p}<0.05)$. At $48 \mathrm{~h}$ after operation, the number of severe pain cases in the observation group was significantly lower than that in the control group ( $\mathrm{p}=0.021$ ); at $72 \mathrm{~h}$ after operation, the number of severe pain cases in the observation group was significantly lower than that in the control group $(\mathrm{p}=0.014)$ (Table IV).

\section{Discussion}

Epidural analgesia has a variety of advantages including rapid onset, small dosage, the exact effect, good controllability, and it has become the preferred method of obstetric surgical anesthesia in China (11). However, there are many adverse reactions of epidural anesthesia, and lower back pain is one of the major. Currently it is considered that postoperative lower back pain is due to the lower back soft tissue injury caused by the puncture during epidural anesthesia in the back. Soft tissue injury can cause local aseptic inflammation, such as periostitis, tendonitis, or cause traumatic edema of the supraspinal ligament and the interspinal ligament (12). DXMS is widely used in the treatment of pain. Epidural postoperative lower back pain is its indications. The side effects DXMS brings to the body is minimal, so it will not bring adverse effect on the quality of patients' lives (13). Therefore, the medical records of 368 cases were retrospectively analyzed, and the effects of DXMS on the prevention of lower back pain in pregnant women after epidural analgesia were summarized.

In this study, the inclusion criteria was strictly enforced and the relevant variables were strictly controlled so as to ensure the validity of the research results. At the same time, repeated examinations on the data processing part of the experiment were conducted to minimize the error of the research results. In this study, the incidence of lower back pain at 48 and $72 \mathrm{~h}$ postoperatively in the observation group was significantly lower than that in the control group, and the incidence of lower back pain in both groups was significantly different at different timepoints $(\mathrm{p}<0.05)$. Therefore, it can be thought that preoperative DXMS can effectively reduce the incidence of postoperative lower back pain in patients with epidural analgesia. In the study of Abd et al (14), they demonstrated that DXMS is absorbed intramuscularly in human tissues and absorbed by tissue vessels. DXMS binds to extracellular receptors and alters the arrangement of cell surface molecules, resulting in decreased permeability of the capillary wall to achieve the role of vasoconstriction and analgesia. In a related study by Rathmell et al (15), they concluded that in epidural surgery, DXMS can inhibit the activation and release of the inflammatory mediators around the injured tissue by inhibiting the synthesis 
of prostaglandins and inhibiting the oxidase activity around the wound site, thereby achieving the analgesic effect of inhibiting spinal nerve root conduction. This corroborates the results in this study that DXMS pretreatment is effective in reducing the incidence of postoperative lower back pain in epidural labor analgesia. In the study of Chau et al (16) and Wilson et al (17), it was shown that the number of punctures is a direct factor affecting postoperative lower back pain. Therefore, the effect of DXMS on patients with different times of punctures was investigated and it was found that either with one puncture or many times of puncture, the incidence of postoperative lower back pain in the observation group was significantly lower than that in the control group. In the study of Chou et al (18), they found that cesarean section led to a variety of complications such as postoperative lower back pain. Therefore, the effect of DXMS on different modes of delivery was also compared, and it was found that both the incidence of postoperative lower back pain in the observation group was significantly lower than that in the control group, either in the case of spontaneous or in the case of cesarean delivery. The result showed that DXMA can reduce the incidence rate of postoperative lower back pain in different delivery mode. In addition, the degree of maternal lower back pain at different time-points after operation was also compared, and it was found that DXMS pretreatment can significantly reduce the degree of lower back pain after postoperative epidural analgesia. In the study by Sharma et al (19), they concluded that the long-term analgesic effect that DXMS exerts was due to long half-life of DXMS and the slower absorption of DXMS in the body, making DXMS perform a long time analgesic effect on the puncture site.

Labor analgesia originated in foreign countries, and it has a history of only more than 100 years. It is a simple, safe and mature technology with a high penetration rate in foreign countries. The analgesia rate in the United States is more than $85 \%$, and more than $90 \%$ in the United Kingdom (20). In China, there are still few hospitals that can perform labor analgesia, and the popularity in China is still very low. Therefore, there are still few studies on labor analgesia. The lack of sample size is also a problem in this study. This study can play an auxiliary role in labor analgesia. With the increase of painless childbirth in China, this study will certainly provide guidance for labor analgesia in the future.

In conclusion, DXMS local pretreatment can reduce the incidence of lower back pain after labor analgesia, and it can reduce the degree of lower back pain. DXMS is beneficial for the prevention of postoperative lower back pain after epidural delivery and deserved to be widely used in clinical treatment.

\section{Acknowledgements}

Not applicable.

\section{Funding}

No funding was received.

\section{Availability of data and materials}

All data generated or analyzed during this study are included in this published article.

\section{Authors' contributions}

ZY and LL designed the study. JM, WG and SL collected the patient data. YJ and YL analyzed the patient data. ZY prepared the manuscript. All authors read and approved the final manuscript.

\section{Ethics approval and consent to participate}

The study obtained the medical Ethics Committee's approval of People's Hospital of Rizhao (Rizhao, China), and all patients and their relatives signed the informed consent form.

\section{Patient consent for publication}

Not applicable.

\section{Competing interests}

The authors have no conflicts of interest to declare.

\section{References}

1. Bateman BT, Mhyre JM, Ehrenfeld J, Kheterpal S, Abbey KR, Argalious M, Berman MF, Jacques PS, Levy W, Loeb RG, et al: The risk and outcomes of epidural hematomas after perioperative and obstetric epidural catheterization: A report from the Multicenter Perioperative Outcomes Group Research Consortium. Anesth Analg 116: 1380-1385, 2013.

2. Kazdal H, Kanat A, Batcik OE, Ozdemir B, Senturk S, Yildirim M, Kazancioglu L, Sen A, Batcik S and Balik MS: Central sagittal angle of the sacrum as a new risk factor for patients with persistent low back pain after caesarean section. Asian Spine J 11: 726-732, 2017.

3. Daly B, Young S, Marla R, Riddell L, Junkin R, Weidenhammer N, Dolan J, Kinsella J and Zhang R: Persistent pain after caesarean section and its association with maternal anxiety and socioeconomic background. Int J Obstet Anesth 29: 57-63, 2017.

4. Cho YH, Kim CK, Heo KH, Lee MS, Ha IH, Son DW, Choi BK, Song GS and Shin BC: Acupuncture for acute postoperative pain after back surgery: A systematic review and meta-analysis of randomized controlled trials. Pain Pract 15: 279-291, 2015.

5. Salem MN, Abbas AM and Ashry M: Dexamethasone for the prevention of neonatal respiratory morbidity before elective cesarean section at term. Proc Obstet Gynecol 6: 1-10, 2016.

6. Nado H, Singh N, Laithangbam P, Devi RS, Alemwapang O and Gangmei FL: A comparative study between propofol and propofol plus dexamethasone as antiemetic during cesarean section under spinal anesthesia. JMS 31: 174-183, 2017.

7. Wahdan AS, El-Sakka AI and Gaafar HMI: The effect of addition of dexamethasone to levobupivacaine in parturients receiving combined spinal-epidural for analgesia for vaginal delivery. Indian J Anaesth 61: 556-561, 2017.

8. Djaladat H, Bruins HM, Miranda G, Cai J, Skinner EC and Daneshmand S: The association of preoperative serum albumin level and American Society of Anesthesiologists (ASA) score on early complications and survival of patients undergoing radical cystectomy for urothelial bladder cancer. BJU Int 113: 887-893, 2014.

9. Li R, Wang C, Lei P, Huang L and Yuan S: Chemical constituents in Flos Sophorae Carbonisatus. Zhongguo Zhong Yao Za Zhi 35: 607-609, 2010 (In Chinese).

10. Ciprandi G, Tosca MA and Silvestri M: Measuring the perception of symptom, drug use and allergen immunotherapy efficacy using the Visual Analogue Scale. Expert Rev Clin Immunol 10: 179-182, 2014.

11. Wang F, Cao YX, Ke SG, Zhu TH and Zhang M: Effect of combined spinal-epidural analgesia in labor on frequency of emergency cesarean delivery among nulliparous Chinese women. Int J Gynaecol Obstet 135: 259-263, 2016.

12. Rosero EB and Joshi GP: Nationwide incidence of serious complications of epidural analgesia in the United States. Acta Anaesthesiol Scand 60: 810-820, 2016. 
13. Mathiesen O, Dahl B, Thomsen BA, Kitter B, Sonne N, Dahl JB and Kehlet H: A comprehensive multimodal pain treatment reduces opioid consumption after multilevel spine surgery. Eur Spine J 22: 2089-2096, 2013.

14. Abd OE, Amadera J, Gomba LA and Pimentel DC: Poster 400 immediate and acute complications following transforaminal epidural steroid injections with dexamethasone. Pain Physician 4: 277-286, 2012.

15. Rathmell JP, Benzon HT, Dreyfuss P, Huntoon M, Wallace M, Baker R, Riew KD, Rosenquist RW, Aprill C, Rost NS, et al: Safeguards to prevent neurologic complications after epidural steroid injections: Consensus opinions from a multidisciplinary working group and national organizations. Anesthesiology 122: 974-984, 2015.

16. Chau A, Bibbo C, Huang CC, Elterman KG, Cappiello EC, Robinson JN and Tsen LC: Dural puncture epidural technique improves labor analgesia quality with fewer side effects compared with epidural and combined spinal epidural techniques: A randomized clinical trial. Anesth Analg 124: 560-569, 2017.

17. Wilson SH, Wolf BJ, Bingham K, Scotland QS, Fox JM Woltz EM and Hebbar L: Labor analgesia onset with dural puncture epidural versus traditional epidural using a 26-gauge whitacre needle and $0.125 \%$ bupivacaine bolus: A randomized clinical trial. Anesth Analg 126: 545-551, 2018.
18. Chou R, Gordon DB, de Leon-Casasola OA, Rosenberg JM, Bickler S, Brennan T, Carter T, Cassidy CL, Chittenden EH, Degenhardt E, et al: Management of postoperative pain: A clinical practice guideline from the American Pain Society, the American Society of Regional Anesthesia and Pain Medicine, and the American Society of Anesthesiologists' Committee on Regional Anesthesia, Executive Committee, and Administrative Council. J Pain 17: 131-157, 2016.

19. Sharma SK, Rogers BB, Alexander JM, McIntire DD and Leveno KJ: A randomized trial of the effects of antibiotic prophylaxis on epidural-related fever in labor. Anesth Analg 118: 604-610, 2014.

20. Gupta N, Gupta S, Agrawal A, Agrawal S, Diwedi S and Singh J: To study the acceptance of epidural analgesia for painless labor at a tertiary care centre. Int J Reprod Contracept Obstet Gynecol 3: 1087-1089, 2014.

This work is licensed under a Creative Commons Attribution-NonCommercial-NoDerivatives 4.0 International (CC BY-NC-ND 4.0) License. 